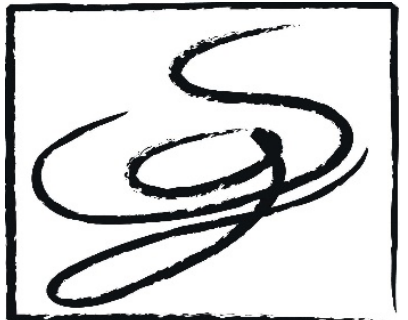

SEMINARIO DE INUESTIGACIÓN DE GÉNERO Y ESTUDIOS GULTURALES

\title{
Espacios: naturaleza, poder y género
}

\author{
Spaces: nature, power, and gender
}

Verónica Pacheco Costa

Universidad Pablo de Olavide,

de Sevilla

vpacheco@upo.es

\author{
Sergio Marín-Conejo \\ Universidad de Sevilla \\ smarin@us.es
}

Amalia Vahí Serrano

Universidad Pablo de Olavide,

de Sevilla

avahser@upo.es

Cada año que pasa suma al repertorio de efemérides nuevas fechas que recordar, acontecimientos notables como los hallazgos científicos, las grandes aportaciones a las artes y a la cultura. Los dos últimos años evidencian que, en las antípodas de aquellas intermitencias de la muerte (Saramago mediante), se han sucedido grandes avances científicos, no solo en el campo de la biomedicina sino también en el conocimiento del espacio, tanto el reconocible como el que no está a nuestro alcance. A unos días de publicarse el presente volumen de AMBIGUA, las agencias espaciales de Estados Unidos, Canadá y Europa anuncian el lanzamiento del telescopio James Webb (JWST) capaz de viajar a lugares desde donde poder observar el pasado ${ }^{1}$. Sobrecoge ver cómo la Ciencia y la Tecnología avanzan por conseguir lo inimaginable siendo así que siempre esperamos la explicación siguiente, la respuesta al para qué servirá. Con toda certeza se conocerán las motivaciones de este y otros experimentos tan retadores, y a buen seguro se podrán encontrar relaciones, argumentos, motivos que expliquen otros tantos procederes de la humanidad. En este mismo año 2021 en que se lanza el JWST, se ha publicado un pequeño corpúsculo dedicado a la memoria y divulgación del trabajo y los desafíos superados por mujeres curiosas y, finalmente, consideradas científicas (GEA. Mujeres que estudian la tierra, 2021). A diferencia de los titulares sobre el telescopio y lo incógnito, el eco social de la sencilla publicación, GEA, radicará probablemente en el desconocimiento sobre mujeres reales que vivieron y dejaron su huella pese a no ocupar titulares ni en su momento ni ahora. Y todo ello aun cuando sus aportes fueron imprescindibles para construir algunos de los pilares de estas agencias espaciales hoy presentes en los medios de comunicación.

\footnotetext{
1 Véase: https://www.bbc.com/mundo/noticias-51011620
} 
Si bien Ambigua ha ido abrazando en su recorrido líneas muy diversas en materia de género y cultura, con el volumen 8 se propone desde la misma perspectiva abordar los escenarios y las relaciones de poder entre sociedad y naturaleza. La complejidad característica de dichas relaciones a lo largo del tiempo perdura y se renueva hasta el punto de generar diferentes revisiones, nuevas discusiones y paisajes renovados que huyen de los estereotipos creativos y relacionales. Así es cómo se plantea un volumen como el presente, en cuyo apartado específico, Espacios: naturaleza, poder y género, y no por casualidad, predominan las aportaciones en contexto iberoamericano.

Entradas ya en la tercera década del siglo, el conocimiento sobre las relaciones humanas no hace sino servir de acicate a la exploración continua y a la descripción de manifestaciones que van desde la creación artística per se a la utilización de ésta para la expresión de identidades en el seno del oikos en sus diferentes acepciones (la casa como significante de todo el acervo ambiental que nos rodea, protege y sustenta). Es aquí donde nos encontramos con la mirada de Alejandra M. Vanegas, en Mujeres y medio ambiente en México y Argentina: colectividades en defensa de la vida; la aportación de Marina Rosenzvaig, Espacio, poder y representación feminista en prácticas teatrales de la región del Noroeste Argentino; el análisis sugerente de Gaojie Lyu, Un viaje espacial y temporal: las mujeres bajo el poder patriarcal y dictatorial en Eni Furtado no ha dejado de correr de Alicia Kozameh, o la descripción singular de algo más que una creación artística, de Sergio R. Recio Saucedo, Mujer Semilla en la resignificación de la identidad de las mujeres de la ciudad de Aguascalientes. En ese mismo universo de América del Sur, Marina Calderón nos traslada a Fronteras cotidianas: intersecciones de espacios de exclusión y resistencia en una experiencia de migración desde América del Sur, un escenario de fronteras en movimiento, por donde se mueven mujeres a través de fronteras físicas y fronteras simbólicas que no por conocidos, muchos de esos relatos, no dejan de sacudir la mente de quien se acerca a ellos. Naturaleza, fronteras, diversidad, relaciones individuo/medio... Un completo repertorio de escenarios que se cierra en este apartado monográfico con Els límits de la llar rural: naturalesa i violencia de Carla Riera, mirando y analizando el sutil contacto entre el interior, el hogar y todo aquello que lo abraza, lo estrecha en no pocas ocasiones, hasta llegar a albergar tensión y violencia tanto dentro como fuera.

Ya en la siguiente sección del volumen 8 encontraremos un repertorio diverso e igualmente rico en las perspectivas en las que nos colocan sus autoras/es. Hallaremos un viaje delicioso por el mundo de los relatos para niños en África, de la mano de Pierre Suzanne Eyenga Onana, que no se limita a reseñar la obra de B. Laure Mebou sino que da un paso más, y en Enfance et didactique des identités de genre dans Plus sage que le roi de Béatrice Laure Mebou levanta su mirada sobre los fundamentos didácticos que los propios niños ejercen en muchos lugares. Con la misma cercanía al relato, pero en otro hemisferio geográfico y bajo un prisma muy diferente, Silvina Diaz se acerca y nos descubre matices en Una aproximación a la escritura dramática femenina en Argentina: la afirmación 
de una mirada propia, dejando al descubierto los patrones que subyacen aun cuando no son deseados, explícitos o llamados a concurrir. Para ello se aproxima a algunas emblemáticas escritoras argentinas de la segunda mitad del siglo XX, como Griselda Gambaro, Aída Bortnik, Susana Torres Molina, Cristina Escofet y Diana Raznovich. Siguiendo la estela discursiva de la creación literaria, Manuela López da un salto a la creación cinematográfica para descubrirnos en Film noir male gaze gender stereotyping in Margaret Atwood's 'the freeze-dried groom' como se perpetúan los roles de género en el llamado cine negro, donde guionistas y escritores no dejan de reproducir estereotipos (mujer fatal, la mujer atrapada, el héroe/detective masculino) que tan exitosos han venido siendo, pese a lo que evidencia la obra de M. Atwood en la que Manuela López se apoya para reforzar su argumentación. Con un sentido implícito igualmente reivindicativo, María de la O Merino nos trae Los Roles de género y la identidad de las mujeres chicanas y latinas en Loverboys de Ana Castillo, autora de esta conocida colección de relatos estereotipados en torno a la joven chicana y sus relaciones con los "activos" del machismo que conocen desde que nacen. Siguiendo el hilo discursivo reivindicativo como llamada a la revisión histórica, Noelia Rozanski presenta en su Bruja gestante. Criminalización patriarcal del cuerpo (no)materno en el acceso al aborto en Argentina un retrato crudo y real del poder de control sobre las conciencias y las voluntades en tiempos muy remotos, pero también contemporáneos por más que los instrumentos y el lenguaje del poder hayan ido adoptando nuevas formas. En Stéphanie Mateu, Intimisme et identité dans l'oeuvre picturale de Santiago Rusiñol i Prats, peintre catalan (1861-1931), Helöise Ducateau retoma la obra de S. Mateu para ahondar en el intimismo que el pintor otorga a sus obra y cómo consigue extraer la información sobre la identidad y esencia de lo que pinta. También ahí se entrevén rasgos de una relación con el paisaje, los jardines, la naturaleza que atrapa en los lienzos.

Cerramos el presente volumen con la aportación de varias lecturas reseñadas en cuatro diferentes aportaciones. Barbara Yanina nos acerca a la última obra de Donna Haraway a través de una reflexión propia en Pensando en pandemia. Seguir con el problema: Generar parentesco en el Chthulceno. Amalia Vahí invita a asomarnos a una deliciosa obra de difusión, Geas. Mujeres Que Estudian La Tierra. Mujeres valientes en la odisea del saber con la que Rosa María Mateos, Ana Ruiz Constán, y las ingeniosas ilustraciones de Nívola Uyá nos traen a nuestro lado a un repertorio de mujeres curiosas que acabaron sumergiéndose en el incómodo pero apasionante mundo científico. Elena Peña y Carlos Rivas consiguen desbrozar las claves orientadoras en materia de género de una obra con clara intención didáctica y propositiva, en Análisis y propuestas educativas sobre género y diversidad sexual: Sociedades y escrituras en continuas transformaciones del equipo editor Jaime Puig Guisado, Cristóbal Torres Fernández y María Rosa Iglesias Redondo.

$Y$ concluye este nuevo número de Ambigua con la reseña que Sergio Marín Conejo hace a Women and Children's Literature. A Love Affair? (2021), de Antonella Cagnolati, en el que Marín alude a la intención 
reivindicativa de la escritora sobre esta producción literaria; en clara referencia a mujeres que escribieron cuentos sobre los que no se termina de reconocer un carácter pedagógico en tanto que creadoras, y no meras relatoras, y posteriormente usurpada por cuentistas varones. El libro reseñado recupera una serie de cuentistas mujeres de varios países europeos. 